\title{
Acute coronary syndromes in octogenarians referred for invasive evaluation: treatment profile and outcomes
}

\author{
Jaguszewski, Milosz ; Ghadri, Jelena-R ; Diekmann, Johanna ; Bataiosu, Roxana D ; Hellermann, Jens \\ P ; Sarcon, Annahita ; Siddique, Asim ; Baumann, Lukas ; Stähli, Barbara E ; Lüscher, Thomas F ; \\ Maier, Willibald ; Templin, Christian
}

\begin{abstract}
BACKGROUND With increasing life expectancy in the western world, the aging population will compose a significant portion of the demographic. Notably, cardiovascular disease is particularly prevalent in the elderly population. The aim of the present study is to investigate the outcomes of octogenarians referred for urgent coronary angiography in the setting of acute coronary syndromes (ACS). METHODS Between June 2007 and June 2012, consecutive patients with ACS were referred for evaluation and percutaneous intervention. Subsequently, the in-hospital death and major adverse cardiovascular events (MACE) at 30 days were analyzed. Multivariate analysis was performed to identify the predictors for death and MACE. RESULTS In patients 80 years $(\mathrm{n}=296)$ ST-segment elevation myocardial infarction (STEMI) occurred in $46.6 \%$, non-ST-segment elevation myocardial infarction (NSTEMI) in $45.9 \%$, and $7.4 \%$ had unstable angina. On the other hand, in patients $<80$ years $(\mathrm{n}=2,316)$ STEMI was observed in $53.4 \%$, NSTEMI in $37.8 \%$ and unstable angina in $9.0 \%$. The primary end-point of total mortality was significantly higher in octogenarians ( 7.4 vs. $4.5 \%, \mathrm{p}=0.026)$. Similarly, the secondary end-point comprising overall MACE rate was significantly higher among the elderly (12.5 vs. $7.3 \%$, $\mathrm{p}=0.002$ ). Within the group of octogenarians, no relation between age and outcomes was noted (for death: OR 0.99, $95 \%$ CI 0.84-1.16, p = 0.915; and for MACE: OR 1.10, $95 \%$ CI 0.88-1.36, p = 0.412); however, in patients < 80 years, age was related to outcomes (for death: OR 1.05, $95 \%$ CI, 1.02-1.08, p $=0.003$; and for MACE: OR 1.03, $95 \% \mathrm{CI}, 1.01-1.05, \mathrm{p}=0.011)$. In a multivariate analysis, systolic blood pressure (OR $0.9795 \%$ CI 0.94-0.99, $\mathrm{p}=0.0058)$, maximal value of creatine kinase (OR 1.00, $95 \%$ CI 1.00-1.00, p = 0.033), and maximal value of NT-proBNP (OR 1.00, $95 \%$ CI 1.00-1.00, p = 0.0225 ) were independent predictors for death, while systolic blood pressure (OR 0.98, $95 \%$ CI 0.96-0.99, $\mathrm{p}=0.0384$ ) and maximal value of C-reactive protein (OR 1.01, $95 \%$ CI 1.00-1.01, p = 0.0265) were associated with overall MACE. CONCLUSIONS Here we confirm that in-hospital death and MACE rate remain significantly elevated in octogenarians in spite of implementation of modern therapies. However, our real-world registry strongly suggests that early revascularization appears safe and effective in elderly patients. Furthermore, we have identified that systolic blood pressure, creatine kinase, NT-proBNP, and C-reactive protein are strong predictors for outcomes in octogenarians.
\end{abstract}

DOI: https://doi.org/10.1007/s00392-014-0756-5

Posted at the Zurich Open Repository and Archive, University of Zurich

ZORA URL: https://doi.org/10.5167/uzh-107617

Journal Article

Published Version 
Originally published at:

Jaguszewski, Milosz; Ghadri, Jelena-R; Diekmann, Johanna; Bataiosu, Roxana D; Hellermann, Jens P; Sarcon, Annahita; Siddique, Asim; Baumann, Lukas; Stähli, Barbara E; Lüscher, Thomas F; Maier, Willibald; Templin, Christian (2015). Acute coronary syndromes in octogenarians referred for invasive evaluation: treatment profile and outcomes. Clinical Research in Cardiology, 104(1):51-58.

DOI: https://doi.org/10.1007/s00392-014-0756-5 


\title{
Acute coronary syndromes in octogenarians referred for invasive evaluation: treatment profile and outcomes
}

\author{
Milosz Jaguszewski · Jelena-R. Ghadri · Johanna Diekmann • Roxana D. Bataiosu • \\ Jens P. Hellermann • Annahita Sarcon • Asim Siddique • Lukas Baumann • \\ Barbara E. Stähli · Thomas F. Lüscher · Willibald Maier · Christian Templin
}

Received: 13 April 2014/ Accepted: 11 August 2014/Published online: 21 August 2014

(C) Springer-Verlag Berlin Heidelberg 2014

\begin{abstract}
Background With increasing life expectancy in the western world, the aging population will compose a significant portion of the demographic. Notably, cardiovascular disease is particularly prevalent in the elderly population. The aim of the present study is to investigate the outcomes of octogenarians referred for urgent coronary angiography in the setting of acute coronary syndromes (ACS).

Methods Between June 2007 and June 2012, consecutive patients with ACS were referred for evaluation and percutaneous intervention. Subsequently, the in-hospital death and major adverse cardiovascular events (MACE) at 30 days were analyzed. Multivariate analysis was performed to identify the predictors for death and MACE.

Results In patients $\geq 80$ years $(n=296)$ ST-segment elevation myocardial infarction (STEMI) occurred in
\end{abstract}

W. Maier and C. Templin authors contributed equally to this work.

Electronic supplementary material The online version of this article (doi:10.1007/s00392-014-0756-5) contains supplementary material, which is available to authorized users.

M. Jaguszewski · J.-R. Ghadri · J. Diekmann ·

R. D. Bataiosu - A. Siddique - L. Baumann ·

B. E. Stähli · T. F. Lüscher · W. Maier · C. Templin ( $₫)$

Department of Cardiology, University Heart Center, University

Hospital Zurich, Raemistrasse 100, 8091 Zurich, Switzerland

e-mail: Christian.Templin@usz.ch

M. Jaguszewski

e-mail: milosz.jaguszewski@usz.ch

J. P. Hellermann

Division of Cardiology, Altstätten Hospital, Altstätten,

Switzerland

A. Sarcon

University of California Davis Medical Center,

Sacramento, CA, USA
$46.6 \%$, non-ST-segment elevation myocardial infarction (NSTEMI) in $45.9 \%$, and $7.4 \%$ had unstable angina. On the other hand, in patients $<80$ years $(n=2,316)$ STEMI was observed in $53.4 \%$, NSTEMI in $37.8 \%$ and unstable angina in $9.0 \%$. The primary end-point of total mortality was significantly higher in octogenarians ( 7.4 vs. $4.5 \%$, $p=0.026)$. Similarly, the secondary end-point comprising overall MACE rate was significantly higher among the elderly ( 12.5 vs. $7.3 \%, p=0.002)$. Within the group of octogenarians, no relation between age and outcomes was noted (for death: OR 0.99, $95 \%$ CI 0.84-1.16, $p=0.915$; and for MACE: OR 1.10, $95 \%$ CI $0.88-1.36, p=0.412$ ); however, in patients $<80$ years, age was related to outcomes (for death: OR 1.05, $95 \%$ CI, 1.02-1.08, $p=0.003$; and for MACE: OR 1.03, $95 \%$ CI, 1.01-1.05, $p=0.011$ ). In a multivariate analysis, systolic blood pressure (OR $0.9795 \%$ CI $0.94-0.99, p=0.0058$ ), maximal value of creatine kinase (OR $1.00,95 \% \mathrm{CI}$ $1.00-1.00, p=0.033$ ), and maximal value of NT-proBNP (OR $1.00,95 \%$ CI $1.00-1.00, p=0.0225)$ were independent predictors for death, while systolic blood pressure (OR 0.98, $95 \%$ CI $0.96-0.99, p=0.0384$ ) and maximal value of C-reactive protein (OR 1.01, $95 \%$ CI 1.00-1.01, $p=0.0265)$ were associated with overall MACE.

Conclusions Here we confirm that in-hospital death and MACE rate remain significantly elevated in octogenarians in spite of implementation of modern therapies. However, our real-world registry strongly suggests that early revascularization appears safe and effective in elderly patients. Furthermore, we have identified that systolic blood pressure, creatine kinase, NT-proBNP, and C-reactive protein are strong predictors for outcomes in octogenarians.

Keywords Acute coronary syndrome - Octogenarians . Invasive treatment 


\section{Introduction}

Cardiovascular diseases remain a major public health concern in the industrialized world, particularly due to an increased prevalence of the elderly population [1]. The World Health Organization (WHO) has estimated that by 2,050 the number of people older than 65 years of age will represent $20 \%$ of the total world's population [2]. Therefore, it is not surprising that the number of octogenarians requiring urgent angiography due to acute coronary syndrome (ACS) has also increased in recent years [3]. Data regarding optimal treatment of the elderly with ACS continue to remain scarce. The current ACS guidelines do not distinguish between elderly and younger patients and recommend early revascularization for symptomatic relief and avoidance of thrombolytics [4-7]. However, in many centers primary percutaneous coronary intervention (pPCI) is not regularly employed in octagenarians [3, 8]. Indeed, elderly patients are underrepresented in clinical trials investigating different treatment strategies that may explain in part why elderly patients with ACS are less likely to receive evidence-based treatment [9, 10].

Previously published observations from the Global Registry of Acute Coronary Events (GRACE) highlighted the need for evidence-based therapies for the elderly with ACS [3]. Given the scarcity of data on outcome of elderly patients with ACS undergoing urgent angiography and pPCI, we investigated outcomes of octogenarians receiving state-of-the-art treatment in a tertiary medical center.

\section{Methods}

\section{Data extraction}

From 2007 to 2012, consecutive patients referred for urgent angiography due to ACS at the University Heart Center of the University Hospital of Zurich were included in the Zurich Acute Coronary Syndrome (Z-ACS) Registry. Secondly, the population was divided into two groups determined base on the age as follows: including patients $\geq 80$ years old $(n=296)$ and below 80 years $(n=2,316)$.

Myocardial infarction was defined based on the definition extracted from Thygesen et al. [11]. ST-segment elevation myocardial infarction (STEMI) was defined as STsegment elevation or left bundle branch block on initial ECG and elevation of cardiac markers. Non-ST-segment elevation myocardial infarction (NSTEMI) was defined in case of angina symptoms and/or ECG changes and elevated cardiac markers. Unstable angina (UA) was diagnosed in presence of angina symptoms and/or ECG changes and normal values of cardiac markers. Stroke was assessed independently by a neurologist and classified based on focal neurologic deficits lasting longer than $24 \mathrm{~h}$ with a clinical relevant lesion visualized on brain imaging. Cardiovascular risk factors were defined as follows: hypertension, diabetes mellitus, and/or dyslipidemia [12]. Family history was considered significant, if a first-degree relative younger than 55 year old (male) or 65 year old (female) suffered premature CVD [12]. Obesity was defined as body mass index $\geq 30 \mathrm{~kg} / \mathrm{m}^{2}$ [12].

Cardiogenic shock was defined as persistent systolic blood pressure (SBP) $<90 \mathrm{mmHg}$ not responsive to fluid resuscitation or requiring vasopressors agents with evidence of pulmonary edema and systemic signs of hypoperfusion [13].

The electronic database $\left(\mathrm{KISIM}^{\circledR}\right)$ provided information regarding baseline characteristics, cardiovascular risk factors, patients' cardiovascular medication on admission, laboratory values, hemodynamic parameters, and the therapeutic modality performed at our institution.

Due to the retrospective nature of this study, the need for informed consent was waived by the institutional review board (local ethics committee of the Canton of Zurich, Switzerland).

\section{Procedures}

Coronary angiography was performed in all patients through the femoral or radial access on an Allura 9, an Allura XPER FD 10/10 (Philips Medical Systems) and Siemens Artis Zee catheterization equipment in the Andreas Gruentzig Catheterization Laboratories of the University Heart Center of the University Hospital Zurich, Switzerland. The protocol consisted of a biplane angiography of the left coronary artery with two radiation exposures in four orientations and of the right coronary artery with two exposures in two orientations. Specific selection of guiding catheters, guidewires, type of stents, thrombectomy were at the operator's discretion. Thrombectomy was performed using the Export catheter, (Medtronic Inc., Tolochenaz, Switzerland). Intravenous heparin was routinely administered with a minimal dose of $5,000 \mathrm{IE}$ or $70-100 \mathrm{IU} / \mathrm{kg}$ to maintain an activated clotting time (ACT) of greater than $250 \mathrm{~s}$. Dual antiplatelet therapy (DAPT) including a loading dose of $600 \mathrm{mg}$ of clopidogrel, $60 \mathrm{mg}$ of prasugrel or $180 \mathrm{mg}$ of ticagrelor [14] and $500 \mathrm{mg}$ of acetylsalicylic acid were provided to all patients before the interventional treatment. After the percutaneous coronary intervention (PCI) procedure, patients were expected to continue DAPT for at least 12 months after discharge, according to current available guidelines.

\section{Outcome records}

The primary end-point was in-hospital all-cause mortality. The secondary end-point included a composite of 
major adverse cardiovascular events (MACE) of death, nonfatal myocardial infarction (MI), stroke and symptom-driven subsequent percutaneous or surgical revascularization. Furthermore, we dichotomized these outcomes into an indicator variable defined by the type of ACS: STEMI or NST-ACS. Patients' outcomes for all-cause in-hospital mortality and MACE were assessed at 30 day of follow-up.

\section{Statistical analysis}

SPSS Statistics 20 (SPSS Inc., Chicago, IL, USA) was used for the statistical analysis. The KSL test for normal distribution was performed. Categorical variables were presented as proportions, and continuous variables as mean values ( \pm standard error of the mean) or as median with interquartile range if the variable was not normally distributed (CK, CK-MB, Troponin T, and proBNP). Comparisons were evaluated by Pearson's Chi square for categorical variables and Student's $t$ test for normally distributed variables. Kruskal-Wallis test was used as nonparametric test. The survival analysis was performed applying the Kaplan-Meier method for both the primary and secondary end-points. The curves were compared using the log-rank-sum test.

In an univariate nominal logistic regression model by age group 80 years or older with all-cause death or MACE as the outcome variables the following prespecified clinical relevant covariates were included: age, heart rate, SBP, aspirin and statin on admission, the use of gylcoprotein IIb/ IIIa inhibitor, maximal values of troponin, creatine kinase, NT-proBNP, and C-reactive protein (CRP) were included. The multivariate logistic regression included all covariates mentioned above to demonstrate changes in significance. A multivariate analysis was also performed to find high-risk subsets of patients $\geq 80$ years who underwent PCI.

All tests were two-sided and a $p<0.05$ was considered as statistically significant.

\section{Results}

Baseline characteristics

Number of octogenarians referred for urgent diagnostic angiography appeared to increase over time (2007-2009 vs. $2010-2012$ : 10.1 vs. $12.5 \%, p=0.58$ ). The percentage of females was significantly higher in octogenarian population as compared to patients $<80$ year old (41.9 vs. $20.7 \%, p<0.001)$. STEMI was more common in younger patients $(p=0.03$, Table 1$)$. Conversely, NSTEMI was more common in the octogenarians. There was no significant difference in the rate of cardiogenic shock (Killip IV) between the populations $(p=0.92$, Table 1$)$. A history of
Table 1 Baseline characteristics

\begin{tabular}{|c|c|c|c|}
\hline Variables & $\begin{array}{l}\geq 80 \text { years } \\
296(11.3 \%)\end{array}$ & $\begin{array}{l}<80 \text { years } \\
2,316(88.7 \%)\end{array}$ & $p$ valu \\
\hline Male & $172(58.1 \%)$ & $1,837(79.3 \%)$ & $<0.001$ \\
\hline Age & $83.6 \pm 0.2$ & $61.3 \pm 0.2$ & $<0.001$ \\
\hline BMI $\left(\mathrm{kg} / \mathrm{m}^{2}\right)$ & $27.4 \pm 1.9$ & $27.4 \pm 0.1$ & $<0.001$ \\
\hline STEMI & $138(46.6 \%)$ & $1,233(53.2 \%)$ & 0.03 \\
\hline NST-ACS & $158(53.4 \%)$ & $1,083(46.8 \%)$ & 0.03 \\
\hline NSTEMI & $136(45.9 \%)$ & $875(37.8 \%)$ & 0.007 \\
\hline UA & $22(7.4 \%)$ & $208(9.0 \%)$ & 0.38 \\
\hline Cardiogenic shock & $28(9.5 \%)$ & $215(9.3 \%)$ & 0.92 \\
\hline \multicolumn{4}{|c|}{ Cardiovascular history } \\
\hline Previous MI & $43(14.5 \%)$ & $233(10.1 \%)$ & 0.017 \\
\hline Stroke & $6(2.0 \%)$ & $24(1.0 \%)$ & 0.13 \\
\hline \multicolumn{4}{|c|}{ Cardiovascular risk factors } \\
\hline HTN & $223(75.3 \%)$ & $1,232(53.2 \%)$ & $<0.001$ \\
\hline DM & $68(23.0 \%)$ & $419(18.1 \%)$ & 0.036 \\
\hline Hyperlipidemia & $104(35.1 \%)$ & $923(39.9 \%)$ & 0.14 \\
\hline Current Smoker & $91(30.7 \%)$ & $1,375(59.4 \%)$ & $<0.001$ \\
\hline Obesity & $32(10.8 \%)$ & $518(22.4 \%)$ & $<0.001$ \\
\hline FH & $52(17.6 \%)$ & $626(27.0 \%)$ & 0.001 \\
\hline \multicolumn{4}{|c|}{ Medication on admission } \\
\hline Aspirin & $165(55.7 \%)$ & $818(35.3 \%)$ & $<0.001$ \\
\hline Clopidogrel & $68(23.0 \%)$ & $303(13.1 \%)$ & $<0.001$ \\
\hline Prasugrel & $1(0.3 \%)$ & $31(1.3 \%)$ & 0.15 \\
\hline Ticagrelor & $1(0.3 \%)$ & 0 & 0.005 \\
\hline Statin & $108(36.5 \%)$ & $704(30.4 \%)$ & 0.023 \\
\hline Beta-Blocker & $118(39.9 \%)$ & $628(27.1 \%)$ & $<0.001$ \\
\hline ACE inhibitor & $71(24.0 \%)$ & $384(16.6 \%)$ & 0.001 \\
\hline Diuretics & $102(34.5 \%)$ & $394(17.0 \%)$ & $<0.001$ \\
\hline ARBS & $57(19.3 \%)$ & $319(13.8 \%)$ & 0.009 \\
\hline $\mathrm{CCB}$ & $43(14.5 \%)$ & $202(8.7 \%)$ & 0.001 \\
\hline Warfarin & $28(9.5 \%)$ & $64(2.8 \%)$ & $<0.001$ \\
\hline
\end{tabular}

Data are presented as $n(\%)$ or mean $( \pm$ SEM)

STEMI ST segment elevation myocardial infarction, NSTACS NonST-segment acute coronary syndrome, NSTEMI Non-ST-segment elevation myocardial infarction, $U A$ unstable angina, $H T N$ hypertension, $D M$ diabetes mellitus, $F H$ known family history, $A C E$ angiotensin-converting enzyme, $A R B S$ angiotensin-receptor blocking agents, $C C B$ calcium-channel blocker

prior MI, hypertension, diabetes mellitus (DM) was more prevalent in those $\geq 80$ years of age. However, cigarette smoking, obesity, and known family history were more common in younger patients. Prior to admission, the use of aspirin and clopidogrel was more common in $\geq 80$ year old than in younger patients $(p<0.001$, Table 1$)$.

Hemodynamics and treatment strategy

By definition, all patients underwent coronary angiography. Primary PCI was performed at similar rates in both groups of 
$\geq 80$ years and $<80$ years $(p=0.98$, Table 2$)$. No differences in the pPCI rate were noted between groups after assigning STEMI vs. NSTEMI groups (Supplemental

Table 2 Hemodynamics and procedural data

\begin{tabular}{|c|c|c|c|}
\hline Variables & $\begin{array}{l}\geq 80 \text { years } \\
296(11.3 \%)\end{array}$ & $\begin{array}{l}<80 \text { years } \\
2,316(88.7 \%)\end{array}$ & $p$ value \\
\hline \multicolumn{4}{|l|}{ Treatment strategy } \\
\hline PCI & $273(92.2 \%)$ & $2,137(92.3 \%)$ & 0.98 \\
\hline CABG & $7(2.4 \%)$ & $89(3.8 \%)$ & 0.20 \\
\hline Conservative & $16(5.4 \%)$ & $90(3.9 \%)$ & 0.21 \\
\hline \multicolumn{4}{|l|}{ Medication acutely } \\
\hline Vesopressors & $20(6.8 \%)$ & $163(7.0 \%)$ & 0.86 \\
\hline GP-IIb/IIIa & $35(11.8 \%)$ & $567(24.5 \%)$ & $<0.001$ \\
\hline GP-IIb/IIIa bolus & $34(11.5 \%)$ & $552(23.8 \%)$ & $<0.001$ \\
\hline GP-IIb/IIIa infusion & $13(4.4 \%)$ & $240(10.7 \%)$ & 0.001 \\
\hline Abciximab & $11(3.7 \%)$ & $297(12.8 \%)$ & $<0.001$ \\
\hline Eptifibatide & $24(8.1 \%)$ & $270(11.7 \%)$ & 0.069 \\
\hline \multicolumn{4}{|l|}{ Emergency procedures } \\
\hline Intubation & $15(5.1 \%)$ & $189(8.2 \%)$ & 0.062 \\
\hline Resuscitation & $36(12.2 \%)$ & $369(15.9 \%)$ & 0.09 \\
\hline Out-of-hospital & $17(5.7 \%)$ & $197(8.5 \%)$ & 0.10 \\
\hline In-hospital & $19(6.4 \%)$ & $172(7.4 \%)$ & 0.53 \\
\hline IABP & $28(9.5 \%)$ & $241(10.4 \%)$ & 0.61 \\
\hline \multicolumn{4}{|c|}{ Vital signs on admission } \\
\hline HR (b.p.m.) & $73.5 \pm 1.0$ & $74.4 \pm 0.3$ & 0.31 \\
\hline $\mathrm{SBP}(\mathrm{mmHg})$ & $132.0 \pm 1.7$ & $125.6 \pm 0.6$ & $<0.001$ \\
\hline DBP (mmHg) & $65.5 \pm 1.0$ & $70.6 \pm 0.3$ & $<0.001$ \\
\hline \multicolumn{4}{|l|}{$\begin{array}{l}\text { Hemodynamic } \\
\text { parameters }\end{array}$} \\
\hline LVEDP (mmHg) & $20.8 \pm 0.6$ & $19.6 \pm 0.2$ & 0.076 \\
\hline LVEF $(\%)$ & $47.7 \pm 1.1$ & $53.1 \pm 0.3$ & $<0.001$ \\
\hline \multicolumn{4}{|l|}{ Location of the lesion } \\
\hline LM & $8(2.7 \%)$ & $38(1.6 \%)$ & 0.19 \\
\hline LAD & $137(46.3 \%)$ & $1,042(45.0 \%)$ & 0.67 \\
\hline LCX & $45(15.2 \%)$ & $461(19.9 \%)$ & 0.054 \\
\hline RCA & $92(31.1 \%)$ & $731(31.6 \%)$ & 0.87 \\
\hline Graft & $14(4.7 \%)$ & $42(1.8 \%)$ & 0.001 \\
\hline \multicolumn{4}{|l|}{$\begin{array}{l}\text { Coronary angiography } \\
\text { findings }\end{array}$} \\
\hline Single vessel & $86(29.1 \%)$ & $983(42.4 \%)$ & $<0.001$ \\
\hline Multi vessel & $209(70.6 \%)$ & $1,313(56.7 \%)$ & $<0.001$ \\
\hline Dissection & 0 & $5(0.2 \%)$ & 0.42 \\
\hline Spasm & $1(0.1 \%)$ & $8(0.3 \%)$ & 0.98 \\
\hline
\end{tabular}

Data are presented as $n(\%)$ or mean $( \pm \mathrm{SEM})$

STEMI ST-segment elevation myocardial infarction, NSTEMI NonST-segment elevation myocardial infarction, $U A$ unstable angina, $I A B P$ intra-aortic balloon pump, $H R$ heart rate, $S B P$ systolic blood pressure, $D P$ diastolic blood pressure, $L V E D P$ left ventricular enddiastolic pressure, $E F$ ejection fraction, $L M$ left main artery, $L A D$ left anterior descending artery, $L C X$ left circumflex artery, $R C A$ right coronary artery
Fig. 1). The surgical revascularization rate was very low, but also similar in both populations $(p=0.20$, Table 2$)$. In $5.4 \%$ of the octogenarians and $3.9 \%$ of population of $<80$ years of age a conservative strategy was chosen $(p=0.21$, Table 2).

Left ventricular ejection fraction (LVEF) was significantly lower in octogenarians as compared to group $<80$ years of age $(p<0.001$, Table 2$)$. SBP was higher with advanced age $(p<0.001)$, while diastolic blood pressure (DBP) was significantly lower in the elderly as compared to patients $<80$ years of age ( $p<0.001$, Table 2 ). The anatomical distribution of infarct-related lesions was similar in both groups (Table 2). Single-vessel disease was less common in octogenarians as compared to younger patients $(p<0.001$, Table 2) and multivessel disease was more prevalent in the elderly population $(p<0.001$, Table 2$)$.

There was no difference between the groups regarding vasopressor administration $(p=0.86$, Table 2$)$ or in the use of intra-aortic balloon pumps (IABP; $p=0.61$, Table 2). Glycoprotein IIb/IIIa antagonists (GP IIb/IIIa) were administered more frequently among younger patients than in octogenarians $(p<0.001$, Table 2$)$. However, the use of GP IIb/IIIa increased among octogenarians over time $(2007 / 09$ vs. $2010 / 12$ : 5.6 vs. $16.5 \%$, $p=0.004)$.

Octogenarians were slightly less likely to receive aspirin $(p=0.039$, Table 1); however, evidence-based dual antithrombotic treatment was similarly applied in both study populations $(p=0.11$, Table 1$)$. Statins and ACE inhibitors were less likely prescribed in octogenarians, while diuretics, angiotensin-receptor blocking agents (ARBS), and warfarin were less commonly used in those $<80$ years of age (Table 1).

\section{Laboratory values}

Troponin $\mathrm{T}$ levels on admission and peak during hospitalization were similar in both groups (Table 3). In contrast, NT-proBNP levels on admission and peak levels during the hospitalization were significantly higher in the patients $>80$ years of age (Table 3 ).

30-day outcomes

The primary end-point of death was significantly higher in octogenarians as compared to those $<80$ years of age ( $p=0.026$, Table 4). However, no difference in the rate of reinfarction was noted ( $p=0.63$, Table 4$)$. The secondary end-point comprising the overall MACE rate was also significantly higher among older population $(p=0.002$; Fig. 1; Table 4). No differences were observed in the rates of stroke $(p=0.18)$, urgent surgical revascularization $(p=0.47)$, and in-stent thrombosis $(p=0.14$, Table 4$)$. 
Only a trend toward more urgent PCI rate was noted in octogenarian patients ( $p=0.054$, Table 4$)$. Additionally, a trend toward a higher mortality in the elderly was documented in STEMI and NST-ACS subgroups (Supplemental Fig. 2). However, elderly patients presenting with NSTEACS had significantly higher MACE rates than younger group (Supplemental Fig. 3).

\section{Predictors of death and MACE}

Interestingly, no relationship between age and outcomes was noted in patients $\geq 80$ years of age; however, among patients $<80$ years old, age was associated with a higher mortality (Supplemental Tables 1-2 and Supplemental Fig. 4). The odds ratios for MACE by a categorized age model showed a clear increasing risk of MACE with age: $<60$ years: OR 0.74 (95\% CI 0.55, 0.99, $p=0.0462$ ), $<70$ years: OR 0.59 (95 \% CI 0.44, 0.78, $p=0.0003$ ), $<80$ years: OR 0.55 (95 \% CI 0.38, 0.81, $p=0.0034$ ), $<85$ years: OR 0.48 (95\% CI 0.26, 0.98, $p=0.0454$ ).

In multivariate analysis, SBP was an independent predictor of death and MACE in all patients, while the peak levels of CRP predicted MACE among patients $\geq 80$ years of age. Similarly, peak levels of creatine kinase and NTproBNP were independent predictors for death in patients of $\geq 80$ years of age. SBP on admission $(p=0.001)$ and CRP on admission ( $p=0.048$ ) were found to be independent risk factors of MACE in the octogenarian population undergoing PCI. Patients with lower SBP and higher CRP had significantly worse outcome as compared to those with higher SBP and lower CRP.

The result of the multivariate analysis is presented in Supplemental Tables 1 and 2.

\section{Discussion}

Our study illustrates several crucial findings. First, the prevalence of octogenarians with ACS admitted to a tertiary medical center with pPCI capacity has increased over time. Second, octogenarians had higher 30-day mortality and a higher MACE rate compared to younger patients in spite of prompt acute revascularization and optimal medical therapy. This difference however, appears to be less than the number reported in previously published series [3, 15, 16]. Third, octogenarians exhibited more comorbidities, extensive coronary artery disease, and lower LVEF compared to younger patients. Finally, age itself was documented as a risk factor for MACE or all-cause death.

No data exist to supporting the notion that octogenarians should be treated differently than younger ACS patients [7]. Indeed, current guidelines on myocardial revascularization suggest similar or even greater benefit of elderly patients from early invasive treatment [7, 17]. However, many studies and registries have documented that elderly patients are less likely to receive evidence-based therapies and are frequently admitted to facilities without a catheterization laboratory and revascularization capabilities [3, 18]. In line with these findings, the GRACE and the Swiss AMIS plus registry documented decreased rates of coronary angiography and PCI in patients of advanced age [3, $8,10]$. One possible explanation for this observation is the

Table 3 Laboratory values

\begin{tabular}{lllr}
\hline Variables & \multicolumn{1}{c}{$\geq 80$} & $<80$ & $p$ value \\
& \multicolumn{1}{c}{$296(11.3 \%)$} & $2,316(88.7 \%)$ & \\
\hline Cholesterol & $4.3( \pm 0.1)$ & $4.9( \pm 0.1)$ & $<0.001$ \\
HDL & $1.2( \pm 0.1)$ & $1.1( \pm 0.1)$ & 0.001 \\
LDL & $2.6( \pm 0.1)$ & $3.2( \pm 0.1)$ & $<0.001$ \\
TG & $1.1( \pm 0.1)$ & $1.4( \pm 0.1)$ & $<0.001$ \\
CRP on ad & $20.5( \pm 2.5)$ & $15.3( \pm 0.8)$ & 0.005 \\
CRP max & $61.4( \pm 5.3)$ & $57.9( \pm 2.0)$ & 0.012 \\
WBC on ad & $9.9( \pm 0.2)$ & $11.1( \pm 0.1)$ & $<0.001$ \\
WBC max & $11.4( \pm 0.3)$ & $12.7( \pm 0.1)$ & $<0.001$ \\
CK on ad & $181.5(46.6)$ & $217.0(351.5)$ & 0.006 \\
CK max & $476.0(186.1)$ & $827.5(1,243.3)$ & $<0.0001$ \\
CK-MB on ad & $35.0(68)$ & $33.0(52.5)$ & 0.7981 \\
CK-MB max & $62.0(197)$ & $91.0(167.5)$ & 0.005 \\
Troponin T on ad & $0.25(0.84)$ & $0.19(0.869)$ & 0.0828 \\
Troponin T max & $1.46(4.89)$ & $1.92(5.01)$ & 0.1986 \\
proBNP on ad & $1803.0(1,291.5)$ & $371.0(4,226)$ & $<0.0001$ \\
proBNP max & $3,716.5(2,322)$ & $1,071.0(7,681.5)$ & $<0.0001$ \\
\hline
\end{tabular}

Data are presented as mean $( \pm \mathrm{SEM}), \mathrm{CK}, \mathrm{CK}-\mathrm{MB}$, Troponin and proBNP are presented as median (IQR)

STEMI ST-segment elevation myocardial infarction, NSTEMI NonST-segment elevation myocardial infarction, $U A$ unstable angina, $H D L$ high-density lipoprotein, $L D L$ low-density lipoprotein, $T G$ triglycerides, $C R P$ c-reactive protein, $W B C$ white blood count, $C K$ creatine kinase, $C K-M B$ creatine kinase-MB fraction, $B N P$ brain natriuretic peptide, on ad on admission

Table 4 Outcomes

\begin{tabular}{llcl}
\hline & \multicolumn{1}{c}{$\begin{array}{c}\geq 80 \text { years } \\
296(11.3 \%)\end{array}$} & $\begin{array}{l}<80 \text { years } \\
2,316(88.7 \%)\end{array}$ & $p$ value \\
\hline Death & $22(7.4 \%)$ & $104(4.5 \%)$ & 0.026 \\
MI & $5(1.7 \%)$ & $31(1.3 \%)$ & 0.63 \\
Stroke & $3(1.0 \%)$ & $9(0.4 \%)$ & 0.18 \\
Urgent PCI & $14(4.7 \%)$ & $63(2.7 \%)$ & 0.054 \\
CABG & 0 & $4(0.2 \%)$ & 0.47 \\
MACE & $37(12.5 \%)$ & $169(7.3 \%)$ & 0.002 \\
\hline
\end{tabular}

Data are presented as $n(\%)$

$C A B G$ coronary artery bypass graft, $M A C E$ major adverse cardiovascular events, $M I$ myocardial infarction, $P C I$ percutaneous coronary intervention 


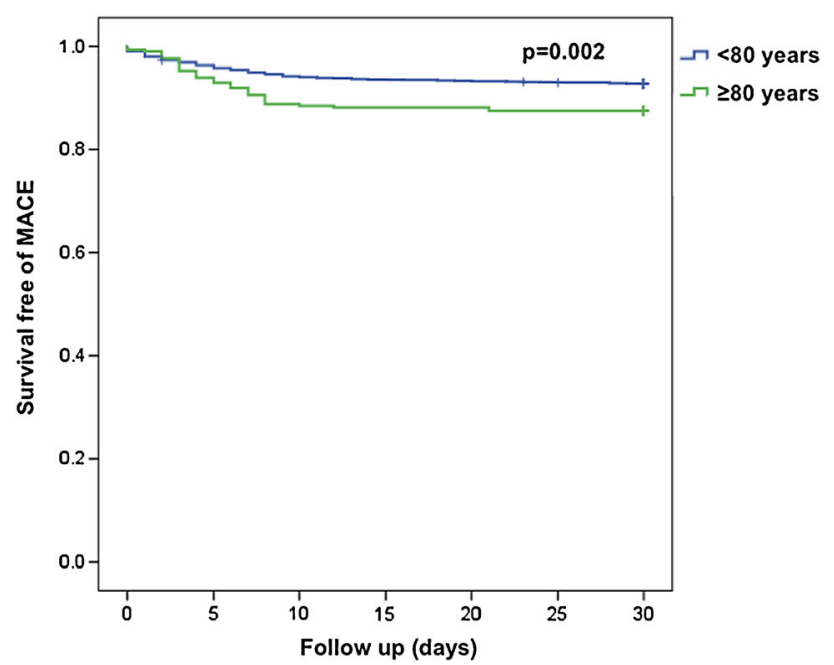

Fig. 1 Kaplan-Meier survival curves for 30-day MACE for $\geq 80$ and $<80$ year old groups demonstrating an unfavorable outcome for patients above $80(p=0.002)$

delay in implementing the proper evidence-based treatment for elderly patients due to the atypical initial presentation and concomitant comorbidities [19,20]. Indeed, the elderly are still underrepresented in randomized controlled trials (RCT) which does not correspond to the clinical practice [3]. Existing data indicate that recruitment of these patients to RCTs could improve their compliance [4]. Also, aggressive interventional approach in the acute course of STEMI or moderate and high-risk NSTEMI could potentially improve outcomes in the oldest subset of patients. A registry, particularly one including data from elderly population is desperately needed to assess outcome and safety of modern management in this growing population. This was our motivation to investigate treatment strategies in octogenarians with ACS referred for urgent intervention. Of note, a trend in increasing number of referrals of octogenarians was observed most recent 3-year observation period compared to 2007 to 2009. In contrast to other previously published studies, we did not observe any significant differences in DAPT therapy or interventional treatment between octogenarians and patients below 80 years of age [3, 21, 22]. Indeed, the rate of interventional approaches including pPCI and bypass surgery to treat ACS was very high regardless of age. Interestingly, contrary to current practice $[3,21,23]$, invasive treatment was similarly applied in patients with NSTE-ACS in both groups of age. It has been demonstrated that routine early invasive strategy can significantly improve cardiovascular outcomes in elderly patients with NSTE-ACS [24].

In our series, the mortality rate was very low in both groups averaging $7.4 \%$ in $\geq 80$ and $4.5 \%$ in those $<80$ years of age. The higher mortality in the elderly in our series is likely related to a higher prevalence of female gender, more comorbidities, more extensive coronary artery disease and a lower LVEF at presentation [22, 25]. Overall, our results are more favorable compared to other large studies, where evidence-based treatment and early revascularization were less frequently implemented in the elderly population $[15,16,26]$. In the Euroheart acute coronary syndrome survey the mortality rate in patients aged $75-84$ was $8.0 \%$ and those $\geq 85$ years of age $16.8 \%$ [15]. In the Maximal Individual Therapy in Acute Myocardial Infarction (MITRA) registry, the in-hospital mortality for patients aged $>75$ years was even higher $(21.8 \%)$ and patients aged $>85$ years showed a mortality rate of $29.4 \%$ when the reperfusion therapy was initiated [16]. The mortality rate in the octogenarian population at our institution is consistent with the German ALKK registry, where interventional treatment of ACS and success rate were relatively high compared to prior studies and registries [27]. This strongly suggests that early revascularization is not only effective but even more beneficial in the elderly population. Stroke was not a safety issue with pPCI in this population in spite of the use of DAPT and a comparable use of glycoprotein IIB/IIIA inhibitors. The relatively low mortality rate is also due to a well-organized healthcare system in Switzerland [28]. Moreover, the use of drug-eluting stents (DES) in more than $80 \%$ patients between 2007 and 2010 may also contributed to the better overall outcome [29].

As anticipated, the primary and secondary end-points were significantly more prevalent in elderly patients. However, in a multivariate analysis, age was an independent predictor for outcomes in younger patients only. This suggests that even very elderly may benefit from early reperfusion. In spite of considerable comorbidities, the elderly have a considerable life expectancy when appropriately treated. Indeed, after stratifying into STEMI and NSTE-ACS, only a trend toward higher mortality rate in octogenarians was observed. However, the groups were probably too small to reach any statistically meaningful conclusion.

As reported previously, maximal values of CRP were associated with poor outcomes in both subpopulations [30]. Only smoking was inversely related to age, possibly because smokers have a shorter life expectancy and, therefore, do not reach older age in similar numbers [31]. The higher inflammatory nature in elderly patients may be worth investigating as a potential issue for further studies.

\section{Limitations}

Our cohort included patients from a single tertiary care center, where all patients were referred for urgent angiography. Data regarding patients treated in conservative 
manner in the referring hospitals are, therefore, lacking. Second, due to the lack of data on comorbidities, we are unable to assess their impact in overall MACE in elderly patients. Furthermore, the study is retrospective in nature; however, the all-comer design minimized selection bias and provided real-life results. Also, most data were collected prospectively in the hospital information system.

\section{Conclusions}

Herein we confirm that in-hospital death and MACE rate remain significantly elevated in octogenarians. In the absence of data from RCTs, real-world registry data such as that from the present Z-ACS registry, strongly suggest that reperfusion using pPCI appears safe and effective despite the age. Furthermore, SBP, creatine kinase, NTproBNP, and CRP are strong predictors for outcomes in octogenarians.

Acknowledgments This study was supported in part by the Swiss National Research Foundation (Special Programme University Medicine Nr. 33CM30-124112/1) and unrestricted Grants by AstraZeneca (Baar, Switzerland), Biosensors (Morges, Switzerland), Eli Lilly (Geneva, Switzerland and Indianapolis, USA), Medtronic (Tolachenaz, Switzerland), and St. Jude (Brussels, Belgium).

\section{References}

1. Gupta A, Mody P, Bikdeli B, Lampropulos JF, Dharmarajan K (2012) Most important outcomes research papers in cardiovascular disease in the elderly. Circ Cardiovasc Qual Outcomes 5:e17-e26

2. Wiener JM, Tilly J (2002) Population ageing in the United States of America: implications for public programmes. Int J Epidemiol 31:776-781

3. Avezum A, Makdisse M, Spencer F, Gore JM, Fox KA, Montalescot G, Eagle KA, White K, Mehta RH, Knobel E, Collet JP, Investigators $G$ (2005) Impact of age on management and outcome of acute coronary syndrome: observations from the global registry of acute coronary events (GRACE). Am Heart J 149:67-73

4. Lee PY, Alexander KP, Hammill BG, Pasquali SK, Peterson ED (2001) Representation of elderly persons and women in published randomized trials of acute coronary syndromes. JAMA 286:708-713

5. Alexander KP, Newby LK, Cannon CP, Armstrong PW, Gibler WB, Rich MW, Van de Werf F, White HD, Weaver WD, Naylor MD, Gore JM, Krumholz HM, Ohman EM (2007) Acute coronary care in the elderly, part I: non-ST-segment-elevation acute coronary syndromes: a scientific statement for healthcare professionals from the American heart association council on clinical cardiology: in collaboration with the society of geriatric cardiology. Circulation 115:2549-2569

6. Alexander KP, Newby LK, Armstrong PW, Cannon CP, Gibler WB, Rich MW, Van de Werf F, White HD, Weaver WD, Naylor MD, Gore JM, Krumholz HM, Ohman EM (2007) Acute coronary care in the elderly, part II: sT-segment-elevation myocardial infarction: a scientific statement for healthcare professionals from the American heart association council on clinical cardiology: in collaboration with the society of geriatric cardiology. Circulation 115:2570-2589

7. Task Force on Myocardial Revascularization of the European Society of C, the European Association for Cardio-Thoracic S, European Association for Percutaneous Cardiovascular I, Wijns W, Kolh P, Danchin N, Di Mario C, Falk V, Folliguet T, Garg S, Huber K, James S, Knuuti J, Lopez-Sendon J, Marco J, Menicanti L, Ostojic M, Piepoli MF, Pirlet C, Pomar JL, Reifart N, Ribichini FL, Schalij MJ, Sergeant P, Serruys PW, Silber S, Sousa Uva M, Taggart D (2010) Guidelines on myocardial revascularization. European heart journal 31:2501-2555

8. Radovanovic D, Urban P, Simon R, Schmidli M, Maggiorini M, Rickli H, Stauffer JC, Seifert B, Gutzwiller F, Erne P, Investigators AP (2010) Outcome of patients with acute coronary syndrome in hospitals of different sizes. A report from the AMIS plus registry. Swiss Med Week 140:314-322

9. Alexander KP, Peterson ED, Granger CB, Casas AC, Van de Werf F, Armstrong PW, Guerci A, Topol EJ, Califf RM (1998) Potential impact of evidence-based medicine in acute coronary syndromes: insights from GUSTO-IIb. Global Use of Strategies to open occluded arteries in acute coronary syndromes trial. J Am Coll Cardiol. 32:2023-2030

10. Vandecasteele EH, De Buyzere M, Gevaert S, de Meester A, Convens C, Dubois P, Boland J, Sinnaeve P, De Raedt H, Vranckx P, Coussement P, Evrard P, Beauloye C, Renard M, Claeys MJ (2013) Reperfusion therapy and mortality in octogenarian STEMI patients: results from the Belgian STEMI registry. Clin Res Cardiol 102:837-845 official journal of the German Cardiac Society

11. Thygesen K, Alpert JS, Jaffe AS, Simoons ML, Chaitman BR, White HD (2012) Third universal definition of myocardial infarction. Nat Rev Cardiol 9:620-633

12. Perk J, De Backer G, Gohlke H, Graham I, Reiner Z, Verschuren M, Albus C, Benlian P, Boysen G, Cifkova R, Deaton C, Ebrahim S, Fisher M, Germano G, Hobbs R, Hoes A, Karadeniz S, Mezzani A, Prescott E, Ryden L, Scherer M, Syvanne M, Scholte op Reimer WJ, Vrints C, Wood D, Zamorano JL, Zannad F (2012) European guidelines on cardiovascular disease prevention in clinical practice (version, 2012) the fifth joint task force of the European society of cardiology and Other societies on cardiovascular disease prevention in clinical practice (constituted by representatives of nine societies and by invited experts). Eur Heart J 2012(33):1635-1701

13. Thiele H, Zeymer U, Neumann FJ, Ferenc M, Olbrich HG, Hausleiter J, Richardt G, Hennersdorf M, Empen K, Fuernau G, Desch S, Eitel I, Hambrecht R, Fuhrmann J, Bohm M, Ebelt H, Schneider S, Schuler G, Werdan K (2012) Intraaortic balloon support for myocardial infarction with cardiogenic shock. N Engl J Med 367:1287-1296

14. Theidel U, Asseburg C, Giannitsis E, Katus H (2013) Costeffectiveness of ticagrelor versus clopidogrel for the prevention of atherothrombotic events in adult patients with acute coronary syndrome in Germany. Clin Res Cardiol 102:447-458 (official journal of the German Cardiac Society)

15. Rosengren A, Wallentin L, Simoons M, Gitt AK, Behar S, Battler A, Hasdai D (2006) Age, clinical presentation, and outcome of acute coronary syndromes in the Euroheart acute coronary syndrome survey. Eur Heart J 27:789-795

16. Haase KK, Schiele R, Wagner S, Fischer F, Burczyk U, Zahn R, Schuster S, Senges J (2000) In-hospital mortality of elderly patients with acute myocardial infarction: data from the MITRA (maximal individual therapy in acute myocardial infarction) registry. Clin Cardiol 23:831-836 
17. Fox KA, Clayton TC, Damman P, Pocock SJ, de Winter RJ, Tijssen JG, Lagerqvist B, Wallentin L (2010) Long-term outcome of a routine versus selective invasive strategy in patients with non-STsegment elevation acute coronary syndrome a meta-analysis of individual patient data. J Am Coll Cardiol 55:2435-2445

18. Mehta RH, Rathore SS, Radford MJ, Wang Y, Krumholz HM (2001) Acute myocardial infarction in the elderly: differences by age. J Am Coll Cardiol 38:736-741

19. Bayer AJ, Chadha JS, Farag RR, Pathy MS (1986) Changing presentation of myocardial infarction with increasing old age. J Am Geriatr Soc 34:263-266

20. Goldberg RJ, Steg PG, Sadiq I, Granger CB, Jackson EA, Budaj A, Brieger D, Avezum A, Goodman S (2002) Extent of, and factors associated with, delay to hospital presentation in patients with acute coronary disease (the GRACE registry). Am J Cardiol 89:791-796

21. Devlin G, Gore JM, Elliott J, Wijesinghe N, Eagle KA, Avezum A, Huang W, Brieger D (2008) Management and 6-month outcomes in elderly and very elderly patients with high-risk non-STelevation acute coronary syndromes: the global registry of acute coronary events. Eur Heart J 29:1275-1282

22. Yan RT, Yan AT, Tan M, Chow CM, Fitchett DH, Ervin FL, Cha JY, Langer A, Goodman SG (2006) Age-related differences in the management and outcome of patients with acute coronary syndromes. Am Heart J 151:352-359

23. Bagnall AJ, Goodman SG, Fox KA, Yan RT, Gore JM, Cheema AN, Huynh T, Chauret D, Fitchett DH, Langer A, Yan AT (2009) Influence of age on use of cardiac catheterization and associated outcomes in patients with non-ST-elevation acute coronary syndromes. Am J Cardiol 103:1530-1536

24. Bach RG, Cannon CP, Weintraub WS, DiBattiste PM, Demopoulos LA, Anderson HV, DeLucca PT, Mahoney EM, Murphy SA, Braunwald E (2004) The effect of routine, early invasive management on outcome for elderly patients with non-ST-segment elevation acute coronary syndromes. Ann Intern Med 141:186-195
25. Gurwitz JH, Osganian V, Goldberg RJ, Chen ZY, Gore JM, Alpert JS (1991) Diagnostic testing in acute myocardial infarction: does patient age influence utilization patterns? The worcester heart attack study. Am J Epidemiol 134:948-957

26. Ko DT, Ross JS, Wang Y, Krumholz HM (2010) Determinants of cardiac catheterization use in older Medicare patients with acute myocardial infarction. Circ Cardiovasc Qual Outcomes 3:54-62

27. Rittger H, Hochadel M, Behrens S, Hauptmann KE, Zahn R, Mudra H, Brachmann J, Senges J, Zeymer U (2012) Age-related differences in diagnosis, treatment and outcome of acute coronary syndromes: results from the German ALKK registry. EuroIntervention 7:1197-1205

28. Ghadri JRJM, Sacron A, Srikantharupan S, Pfister P, Siddique A, Kaufmann PA, Wyss CA, Gaemperli O, Landmesser U, Altwegg L, Maier W, Corti R, Lüscher TF, Templin C (2013) Current outcome of acute coronary syndromes: data from the zurich-acute coronary syndrome (Z-ACS) registry. Cardiovasc Med 16:115-122

29. Raber L, Kelbaek H, Ostojic M, Baumbach A, Heg D, Tuller D, von Birgelen C, Roffi M, Moschovitis A, Khattab AA, Wenaweser P, Bonvini R, Pedrazzini G, Kornowski R, Weber K, Trelle S, Luscher TF, Taniwaki M, Matter CM, Meier B, Juni P, Windecker S (2012) Effect of biolimus-eluting stents with biodegradable polymer vs bare-metal stents on cardiovascular events among patients with acute myocardial infarction: the COMFORTABLE AMI randomized trial. JAMA 308:777-787

30. Fiechter M, Ghadri JR, Jaguszewski M, Siddique A, Vogt S, Haller RB, Halioua R, Handzic A, Kaufmann PA, Corti R, Luscher TF, Templin C (2013) Impact of inflammation on adverse cardiovascular events in patients with acute coronary syndromes. J Cardiovasc Med 14:807-814 (Hagerstown)

31. Devlin W, Cragg D, Jacks M, Friedman H, O'Neill W, Grines C (1995) Comparison of outcome in patients with acute myocardial infarction aged $>75$ years with that in younger patients. Am J Cardiol 75:573-576 